\title{
Modeling and Simulating Empires: Toward a Game World Generator
}

\author{
Barry G. Silverman \\ Electrical and Systems Engineering Department, \\ University of Pennsylvania, Philadelphia, USA \\ basil@seas.upenn.edu
}

\begin{abstract}
This talk enumerates the challenges of building a game generator that works like the SimCity and/or empire building genre of games. This talk begins by describing a universally recurring socio-cultural "game" of inter-group competition for control of resources. It next describes efforts to author a game generator and software agents able to play the game as real humans would - which suggests the ability to study alternative ways to influence them, observe effects, and potentially understand how best to alter the outcomes of dysfunctional economies and potential conflict situations. I then examine two implemented game worlds (NonKin Village and FactionSim Countries). I conclude by arguing that substantial effort on game realism, best-of-breed social science models, and agent validation efforts is essential if analytic experiments are to effectively explore alternative ways to influence outcomes.
\end{abstract}

